\section{Duodenal mucosa-associated lymphoid tissue lymphoma masquerading as an ulcer scar}

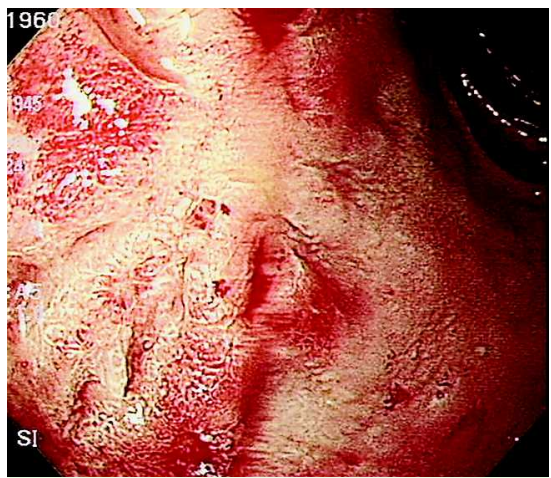

Fig. 1 Endoscopic view. Reddish ulcer scar with fold convergence was noted on the anterior wall of the duodenal bulb. The surrounding mucosa showed patchy erythema and friability. Blood oozed from the ulcer scar after light touch by the scope.

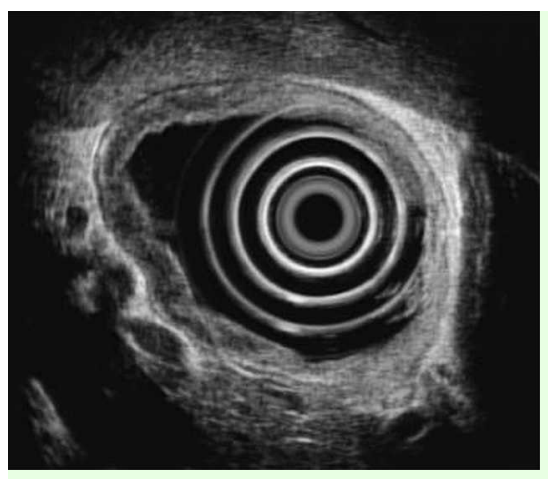

Fig. 2 Endoscopic ultrasound image of hypoechoic wall thickening of the second sonographic layer and focal interruption of the third layer of the duodenal wall.

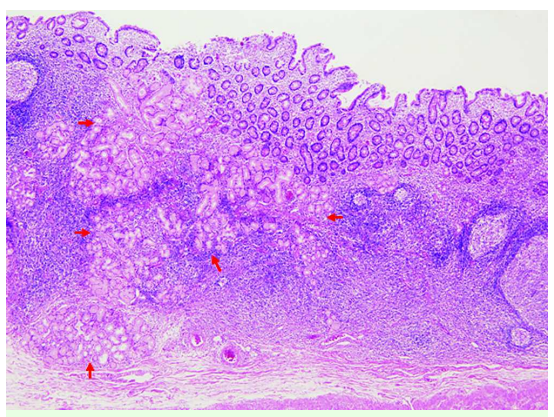

Fig. 3 Photomicrograph of duodenal bulb showing diffuse subepithelial infiltration of atypical lymphocytes into the mucosal and submucosal layer. The red arrows show submucosal Brunner's glands, indicative of duodenum (hematoxylin and eosin, $\times 40$ ).
A 62-year-old man was referred to our clinic because of gastric malignancy found on a periodic medical check-up. He had no specific symptoms or signs. Physical examination and routine laboratory studies were normal. Esophagogastroduodenoscopy revealed early gastric cancer (EGC) in the antrum, and there was an additional reddish ulcer scar with fold convergence in the anterior wall of the duodenal bulb. Unlike typical ulcer scar tissue, its mucosa showed patchy erythema and friability. Blood oozed after light touch by the scope ( $\odot$ Fig. 1 ). Thus, a biopsy specimen was also taken from the duodenal bulb. Interestingly, histology showed infiltration of atypical lymphocytes with lymphoepithelial lesions. Endoscopic ultrasound (GF-UM 2000, Olympus, Tokyo, Japan) demonstrated hypoechoic wall thickening of the second sonographic layer and focal interruption of the third layer of the duodenum ( $\bullet$ Fig. 2). There were no abnormalities in bone marrow biopsy, abdomen and chest computed tomography scan. He underwent subtotal gastrectomy 4 weeks later. Histological examination revealed that atypical lymphocytes infiltrated diffusely into the mucosal and submucosal layer of the duodenal bulb ( Fig. 3 ). Mucosa-associated lymphoid tissue (MALT) lymphoma rarely affects the duodenum. To date, there have been 19 cases of primary duodenal MALT lymphoma in the English literature. Endoscopic features of duodenal MALT lymphoma include irregular bumpy mucosa, ulceration, and polypoid appearance. Of the 19 cases, six had ulceration (active ulcers) [1 -4]. The life cycle of the malignant ulcer is well known in EGC [5]. Therefore, it could appear to be healed. We think that even duodenal MALT lymphoma that forms an ulcer crater may be healed to resemble an ulcer scar like this. Contrary to gastric ulcer, most duodenal ulcers do not need biopsy. In this case, if a biopsy had not been taken from the duodenum, it would have been regarded as a simple ulcer scar. Therefore, endoscopic biopsies are mandatory even for duodenal ulcer scars, if they seem to be slightly atypical.
S. J. Cho ${ }^{1}$, K. W. Ryu ${ }^{1}$, C. G. Kim ${ }^{1}$, J. Y. Lee ${ }^{1}$, M. C. Kook ${ }^{1}$, H. S. Min' ${ }^{2}$, I. J. Choi ${ }^{1}$

Center for Gastric Cancer, Research Institute and Hospital, National Cancer Center, Korea

Department of Pathology, Research Institute and Hospital, National Cancer Center, Korea

\section{References}

1 Lepicard A, Lamarque D, Levy $M$ et al. Duodenal mucosa-associated lymphoid tissue lymphoma: treatment with oral cyclophosphamide. Am J Gastroenterol 2000; 95: 536-539

2 Nakamura S, Matsumoto T, Kusano $Y$ et al. Duodenal mucosa-associated lymphoid tissue lymphoma treated by eradication of $\mathrm{He}$ licobacter pylori: report of 2 cases including EUS findings. Gastrointest Endosc 2001; 54: $772-775$

3 Wang HH, Lin JT, Chiu CC et al. Endoscopic features of mucosa-associated lymphoid tissue lymphoma of the duodenum. Gastrointest Endosc 1995; 41: $258-261$

4 Patel VG, Eltayeb OM, Henderson VJ et al. Primary duodenal low-grade mucosa-associated lymphoid tissue lymphoma presenting with outlet obstruction. Am Surg 2004; 70: 613-616

5 Sakita T, Oguro Y, Takasu S et al. Observations on the healing of ulcerations in early gastric cancer. The life cycle of the malignant ulcer. Gastroenterology 1971; 60: $835-839$

Bibliography

DOI 10.1055/s-2007-995805

Endoscopy 2008; 40: E175

(c) Georg Thieme Verlag KG Stuttgart · New York ISSN 0013-726X

Corresponding author

I. J. Choi, MD, PhD

Center for Gastric Cancer

National Cancer Center

809 Madu 1-dong

Ilsandong-gu, Goyang

Gyeonggi, 411-769

Korea

Fax: +82-31-9201127

cij1224@ncc.re.kr 